\title{
Author Correction: Dynamic intercellular transport modulates the spatial patterning of differentiation during early neural commitment
}

\author{
Chad M. Glen ${ }^{1}$, Todd C. McDevitt ${ }^{2,3} \&$ Melissa L. Kemp (iD ${ }^{1}$
}

Correction to: Nature Communications; https://doi.org/10.1038/s41467-018-06693-1; published online 05 October 2018

In the original version of this Article, an incorrect DOI number was provided in the Code Availability statement regarding the deposition of the computational model. The correct DOI is 10.5281/zenodo.1413539. This error has been corrected in both the PDF and HTML versions of the Article.

Published online: 16 November 2018

\begin{abstract}
(c) (i) Open Access This article is licensed under a Creative Commons Attribution 4.0 International License, which permits use, sharing, adaptation, distribution and reproduction in any medium or format, as long as you give appropriate credit to the original author(s) and the source, provide a link to the Creative Commons license,

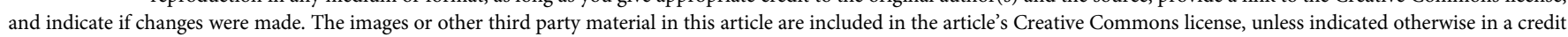

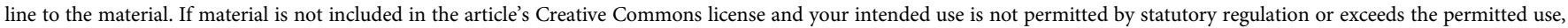
you will need to obtain permission directly from the copyright holder. To view a copy of this license, visit http://creativecommons.org/licenses/by/4.0/.
\end{abstract}

(C) The Author(s) 2018

\footnotetext{
${ }^{1}$ The Wallace H. Coulter Department of Biomedical Engineering, Georgia Institute of Technology and Emory University, Atlanta, GA 30332, USA. ${ }^{2}$ Gladstone Institute of Cardiovascular Disease, San Francisco, CA 94158, USA. ${ }^{3}$ Department of Bioengineering \& Therapeutic Sciences, University of California, San Francisco, CA 94158, USA. Correspondence and requests for materials should be addressed to T.C.M. (email: todd.mcdevitt@gladstone.ucsf.edu) or to M.L.K. (email: melissa.kemp@bme.gatech.edu)
} 